\title{
Journal of Thoracic Imaging
}

Should stress myocardial perfusion MRI be routinely added to delayed enhancement cardiac MRI studies?

--Manuscript Draft--

\begin{tabular}{|l|l|}
\hline Manuscript Number: & \\
\hline Full Title: & $\begin{array}{l}\text { Should stress myocardial perfusion MRI be routinely added to delayed enhancement } \\
\text { cardiac MRI studies? }\end{array}$ \\
\hline Article Type: & Expert Opinion Response \\
\hline Corresponding Author: & $\begin{array}{l}\text { Jan Bogaert } \\
\text { BELGIUM }\end{array}$ \\
\hline Corresponding Author's Institution: & Jan Bogaert \\
\hline Order of Authors: & \\
\hline
\end{tabular}


Cardiac magnetic resonance (CMR) offers nowadays a patient and disease tailored approach. Assessment of myocardial perfusion, using the first pass of contrast through the heart, in rest and during stress conditions, enables to detect the presence of hemodynamically significant stenoses. They present as regions of the myocardium that do not enhance during first pass imaging typically following coronary perfusion territories. This technique combines high specificity and sensitivity, and is typically part of a more comprehensive assessment including function and viability imaging. It should be riserved to those patients in whom there is a clinical suspicion or question of myocardial ischemia. 


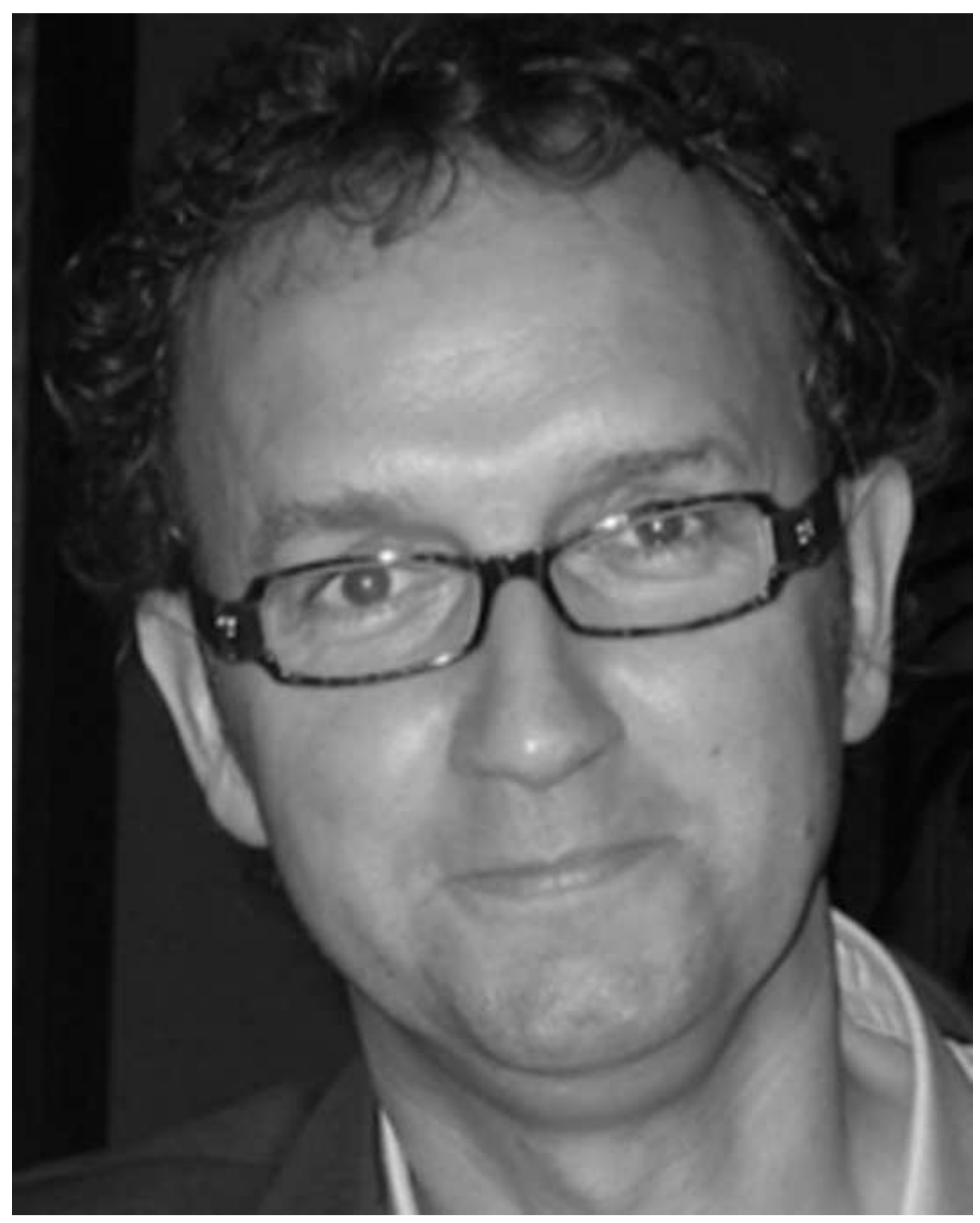

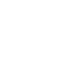


${ }^{*}$ Copyright Transfer and Disclosure Form
Click here to download Copyright Transfer and Disclosure Form: copyrightTransfer.pdf

*Copyright Transfer and Disclosure Form
Click here to download Copyright Transfer and Disclosure Form: copyrightTransfer.pdf

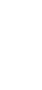

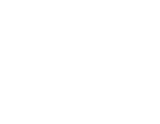

$\sqrt{2}$

(1)

(1)
(1)

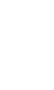
(1)

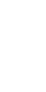
(1) . . . .

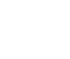

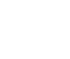

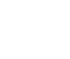
. . . . . . . . . . . . . . . . . . . . . . . . . 